\title{
Effect of Stitch Length on the Physical Properties of Both Plain and 1 X 1 Rib Knitted Fabrics
}

\author{
Ichetaonye SI ${ }^{1 *}$, Ichetaonye DN¹, Adeakin OAS ${ }^{1}$, Tenebe OG ${ }^{2}$, Yibowei ME ${ }^{1}$ and Dawodu OH ${ }^{1}$ \\ ${ }^{1}$ Department of Polymer and Textile Technology, Yaba College of Technology, Yaba, Lagos, Nigeria \\ ${ }^{2}$ Department of Home Economics, Federal College of Education, Kontagora, Nigeria
}

\begin{abstract}
The Effect of the Stitch length on the properties of plain and 1x1 rib knitted fabric was carried out. Fabrics with various stitch length determined by the stitch dial at 4, 6, 8 and 10 were knitted using the flat bed machine for plain knitted fabric and the v-bed machine for $1 \times 1$ rib knitted fabric separately. The knitted fabrics with stitch length (Plain) $0.67 \mathrm{~cm}, 0.84 \mathrm{~cm}, 0.86 \mathrm{~cm}, 0.94 \mathrm{~cm}$ and also ( $1 \times 1 \mathrm{Rib}) 0.8 \mathrm{~cm}, 1.04 \mathrm{~cm}, 1.06 \mathrm{~cm}$ and $1.08 \mathrm{~cm}$ were tested separately for linear density, weight, tightness factor, thickness factor, elastica factor and stitch density of the fabric and the results show that significantly they differ. The results show that the higher the stitch length the more loose the loops hence the structure of the fabric and the shorter the stitch length the tighter or compact the fabric is.
\end{abstract}

Keywords: Stitch length; Knitted fabric; Stitch dial; Flat bed; V-bed

\section{Introduction}

Knitted fabrics are textile structure assembled from basic construction unit called loops and there exist two basic technologies for manufacturing knitting structures namely weft and warp (Figure 1). The weft knitted fabric can be manufactured using circular or flat knitting machine and every form can have various configurations depending on the machine performance [1]. Thus, all weft knitted fabric are based on one of the three basic structures either plain, rib or purl and their stitches can also be used for decorative pattern designs [2]. The simplest weft structure produced by the needles of a single flat bed machine is called Plain knit or Jersey knit while the structures obtained from the production of a double flat bed machine inclined in an inverted $\mathrm{v}$-shape at $90^{\circ}$ is called Rib structure [2,3].

However, jersey is used predominantly for clothing manufacture and has different appearance on both side of the fabric. The fabric posses some high stretchy features, light weighted and most often used for T-shirts, dresses, woman's tops, ladies suiting as well as sucks [4]. In knitting, ribbing is a pattern in which vertical stripes of stockinette stitch alternates with vertical stripes of reverse stockinette. This is noted by (number of knit stitches) Figure 2 by (number of purl stitches) having the same appearance on both side of the fabric [5]. Rib structure causes fabric to pull - in due to its narrow width which can extend to the same width as the plain fabric used for producing welts (Figure 3), close fitting garments and can be composed of any structural combination of $1 \times 1,2 \times 2,3 \times 3$, etc [3].

It is interesting that the process of yarn conversion into a weft knitted fabric can be performed from only one yarn package, which is a substantial advantage regarding the process preparation. Hence, due to the curved structure of the loop (Figure 4), the weft knitted structure are mostly elastic, stretchable and easily deformed [6,7].

\section{Objectives}

1. To determine what effect does stitch length have on plain and $1 \times 1$ rib knitted fabric.

2. To compare their various physical properties.

3. To determine what environmental conditions are both fabrics preferably be used.

\section{Experimental}

\section{Equipment and materials}

1. Flat bed knitting machine

2. V-bed knitting machine

3. Pilling Box

5. Weighing Machine

6. Comb

7. Dead weight

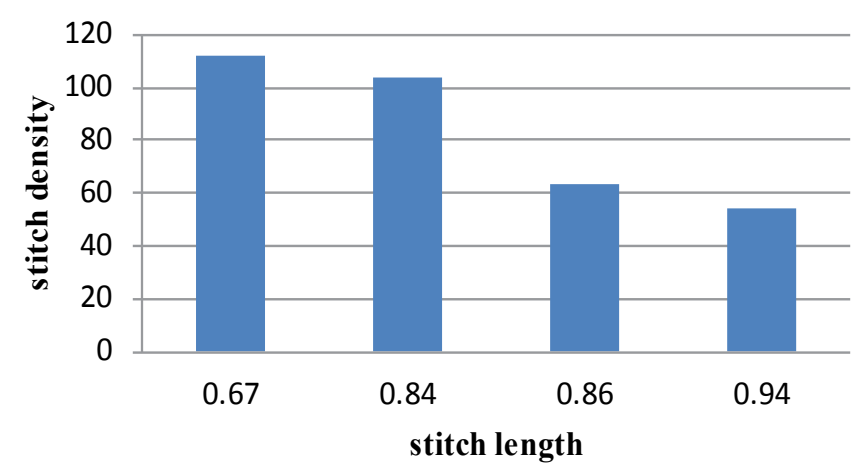

Plain Knitted Fabric

Figure 1: Stitch density with respect to stitch length.

${ }^{*}$ Corresponding author: Ichetaonye SI, Department of Polymer and Textile Technology, Yaba College of Technology, Yaba, Lagos, Nigeria, Tel: +2348032462301; E-mail: ik4simon@yahoo.com

Received November 02, 2014; Accepted December 03, 2014; Published December 06, 2014

Citation: Ichetaonye SI, Ichetaonye DN, Adeakin OAS, Tenebe OG, Yibowei ME et al. (2014) Effect of Stitch Length on the Physical Properties of Both Plain and 1 X 1 Rib Knitted Fabrics. J Textile Sci Eng 4: 177. doi:10.4172/2165-8064.1000177

Copyright: (C) 2014 Ichetaonye SI, et al. This is an open-access article distributed under the terms of the Creative Commons Attribution License, which permits unrestricted use, distribution, and reproduction in any medium, provided the original author and source are credited. 
Citation: Ichetaonye SI, Ichetaonye DN, Adeakin OAS, Tenebe OG, Yibowei ME, et al. (2014) Effect of Stitch Length on the Physical Properties of Both Plain and 1 X 1 Rib Knitted Fabrics. J Textile Sci Eng 4: 177. doi:10.4172/2165-8064.1000177

Page 2 of 5

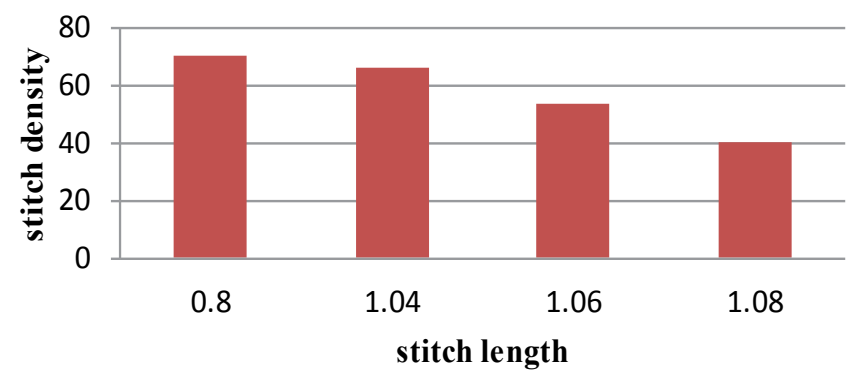

$1 \times 1$ rib knitted fabric

Figure 2: Stitch density with respect to stitch length.

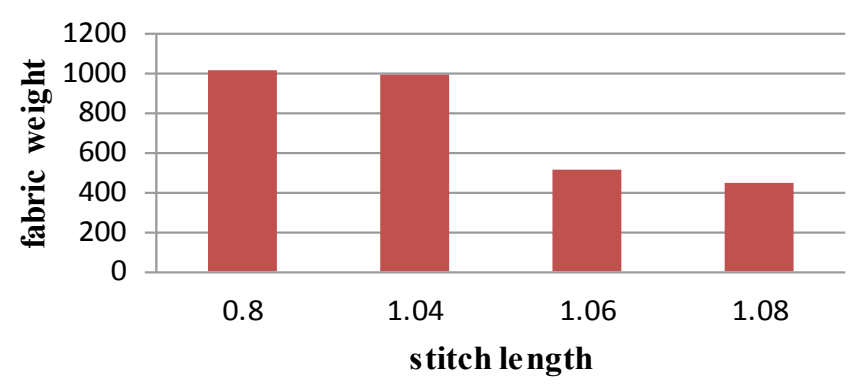

Figure 3: Fabric weight with respect to stitch length.

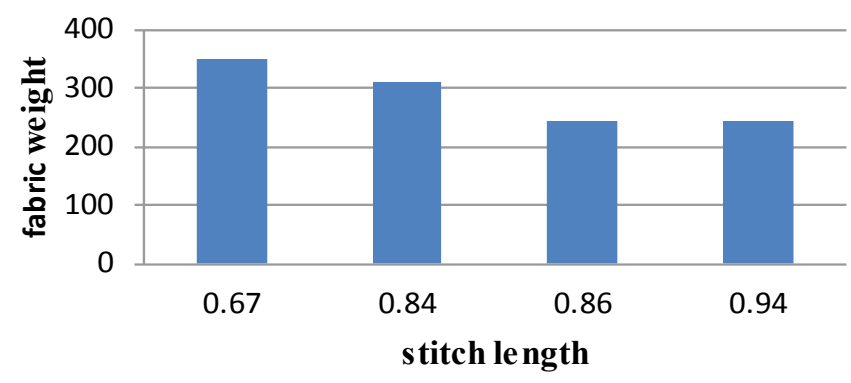

Figure 4: Fabric weight with respect to stitch length.

5. Cotton yarn (various colours and count)

6. Engine oil for lubrication

7. Alternating comb

\section{Procedure for knitting}

Plain knitted fabric on a single flat bed machine: A group of 50 adjacent needles about the middle of the machine were raised to the knitting zone. A knitting yarn was passed through various guides, tension devices and to the feeding point of the cam-box (Figure 5). With the yarn held at its tip underneath the cam-box, the needles were alternated and the cam-box was traversed across the needle bed from right to left. The knitting comb was hung on the course to facilitate the processes of knock-over, the alternated needle was brought back to the knitting zone and then 150 courses was knitted for stitch dial 4, 6, 8 and 10 respectively. Then the fabric was pressed-off.

$1 x 1$ Rib fabric on a v-bed machine: A group of 25 adjacent needles alternatively located about the middle of the machine on both the front and back needle bed were raised to the knitting zone (Figure 6). A knitting yarn was passed through various guides and tension devices to the feeding point of the cam-box and with the yarn held underneath the cam-box at its tip, the cam-box was traversed once across the needle beds (Figure 7). The knitting comb was hung on the course, the diagonal raising cams was set to all knit, 150 courses was knitted for stitch dial 4, 6, 8 and 10 respectively and the fabric was pressed-off

\section{Measuring stitch length}

After knitting 150 courses with 50 needles on the flat bed and the $\mathrm{v}$-bed machine for each stitch dial and press-off, three (3) courses were unraveled from each separate sample until regular knitting is obtained. With the aid of a sharp scissors the last loop of the fabric selvedges are cut off, two (2) spots were made using a marker on both edges of the fabric, the yarn of the next course was removed and measured on a mater-rule. This was repeated three (3) times and the average was recorded which is the "COURSE LENGTH".

Mathematically

$S . L=\frac{C . L}{N}$

Where S.L $=$ Stitch Length

C.L $=$ Course Length

$\mathrm{N}=$ No. of Needles

This was repeated for stitch dial 4, 6, 8 and 10 respectively for both plain and rib fabric.

\section{Tightness factor}

$$
T . F=\frac{\sqrt{T}}{L}
$$

Where T.F $=$ Tightness Factor

$\mathrm{T}=$ The linear density of yarn in Tex

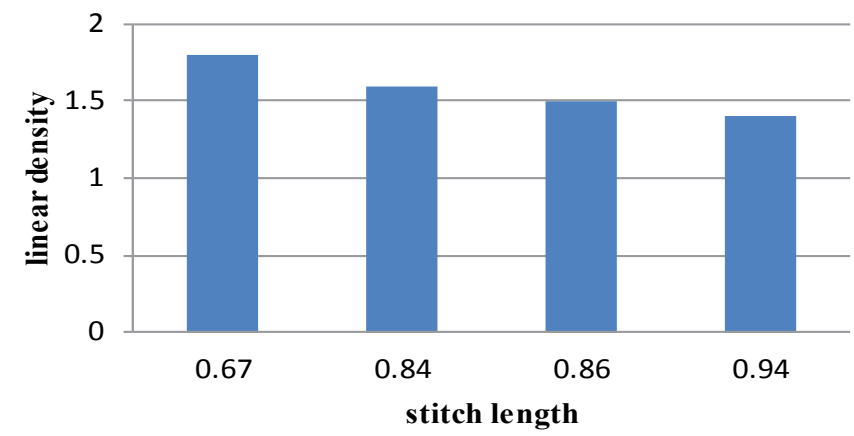

Figure 5: Linear density with respect to stitch length.

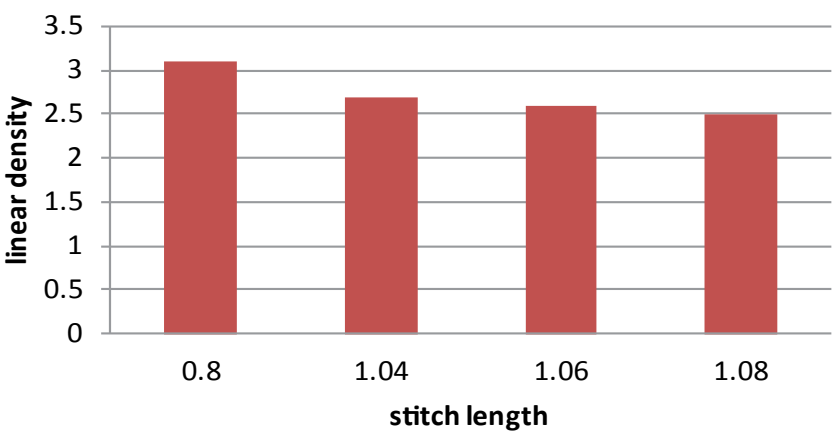

Figure 6: Linear density with respect to stitch length. 
Citation: Ichetaonye SI, Ichetaonye DN, Adeakin OAS, Tenebe OG, Yibowei ME, et al. (2014) Effect of Stitch Length on the Physical Properties of Both Plain and 1 X 1 Rib Knitted Fabrics. J Textile Sci Eng 4: 177. doi:10.4172/2165-8064.1000177

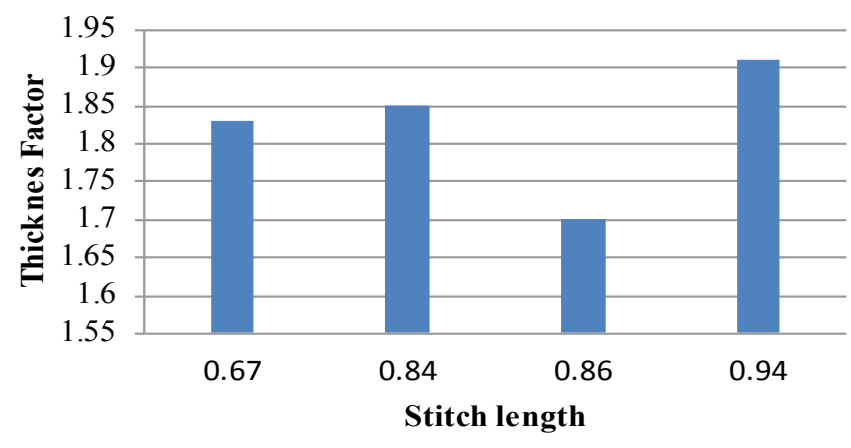

Figure 7: Thickness factor with respect to Stitch length.

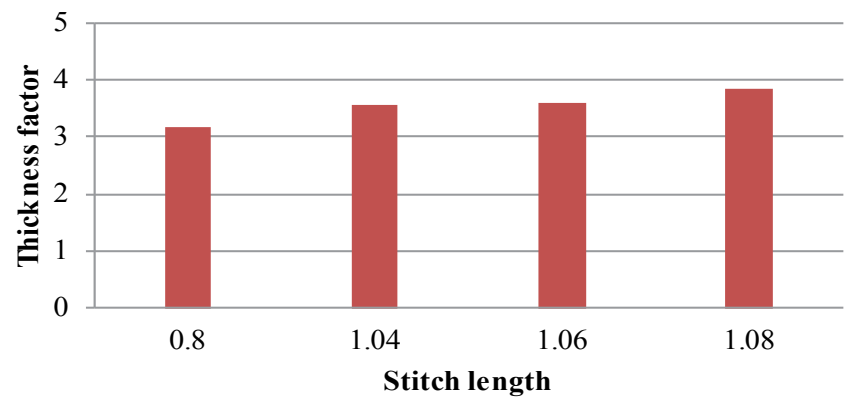

Figure 8: Thickness factor with respect to Stitch length.

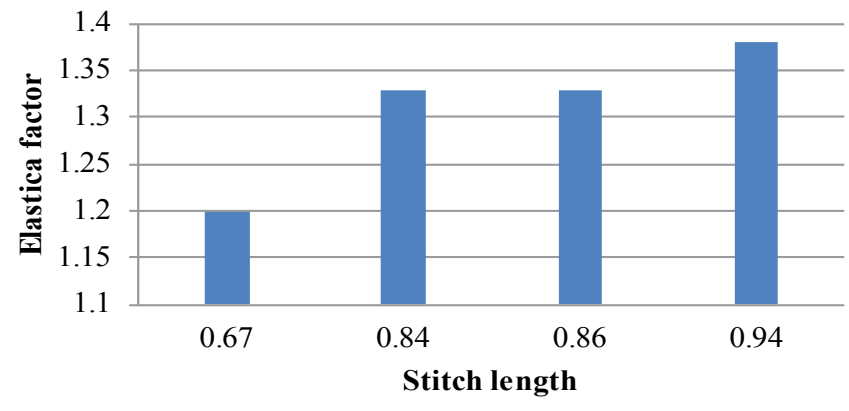

Figure 9: Elastica with respect to Stitch length.

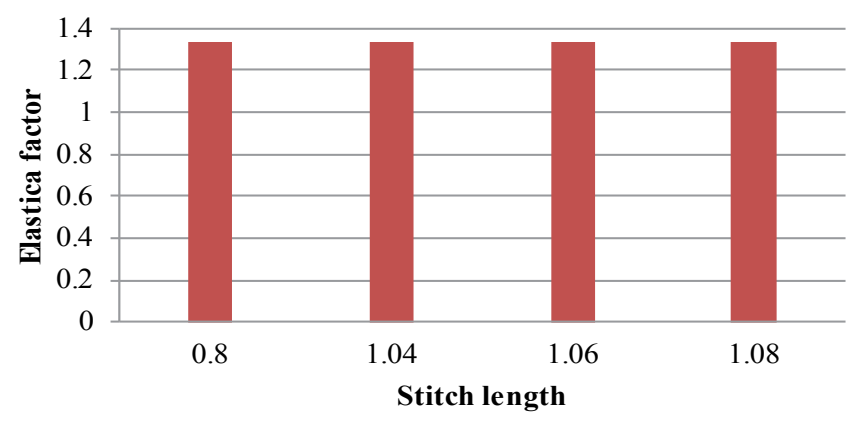

Figure 10: Elastica with respect to Stitch length.

$\mathrm{L}=$ Stitch length or loop length in $\mathrm{cm}$

\section{Elastica factor}

Mathematically

$$
\begin{aligned}
& E=\frac{b}{a} \\
& \text { Where } \mathrm{b}=\text { the height of the loop } \\
& \mathrm{a}=\text { the width of the loop }
\end{aligned}
$$

\section{Pilling}

The pilling test for each fabric was carried out in ICI Pill Box. Four 5 "x 5" samples of each loop length (2 in course direction, 2 in wale direction) were sewn and fitted round four rubber tubes (Figure 8). The cut ends were sealed with sellotape and brushed on the machine for 4 minutes \pm 10 seconds, and then two are mounted face up on the second rotating platform while the other two are face down in contact with the first two. After 2 minutes \pm 10 seconds of rubbing, the two upper specimens are evaluated for pilling.

\section{Washing shrinkage}

Eight (8) specimens, four (4) for each type (plain and rib) were spread on the table and a glass template of square size was placed each on them. There were six marks on the glass template with distance between two marks to be $50 \mathrm{~mm}$ (Figure 9). Each specimen were marked with a marker and then sewn by hand sewing machine. Each specimen was washed at $60^{\circ} \mathrm{C}$ for 90 minutes with liquid soap and then taken out for drying using the flat drying method. After drying, each specimen was re-weighed and the shrinkage percentage (\%) was determined using

$$
\text { Shrinkage } \%=\frac{(L b-L a)}{L a} \times 100
$$

Where $\mathrm{L}_{\mathrm{b}}=$ Length of fabric before wash

$\mathrm{L}_{\mathrm{a}}=$ Length of fabric after wash

\section{Wbrasion resistance}

Eight (8) circular specimens of $38 \mathrm{~mm}$ in diameter were cut using a cutting die i.e. four (4) each for plain and rib. The specimen was weighed to determine the pre-test mass for each dial (Figure 10). Four (4) specimen holders from the Martindala tester were removed and each cut specimen was placed with the technical face down into the gold ring. After which the handle was screwed back on and each assemble holders were placed into the machine, while the silver caps and black knobs are replaced. The required weight was added by resting the weights on the end of the handles ( $\mathrm{Kpa}=1$ kilo pascal) then the counter system to record the desired movements was set to run a batch of 500. After the batch was completed, the specimen holders were taken off weighed and the percentage differences recorded.

\section{Discussion}

Judging from the structures and the various analyses, the following observations were made,

As the fabric got tighter, two situations were observed;

A. The stitch length size reduces because of the compactness of the fabric and the reduced stitch dial used.

B. The stitch density increases because of the small size of the stitch length of the knitted fabric based on its compactness.

As seen from Tables 1 and 2 the plain and the $1 \mathrm{x} 1$ rib knitted fabric for stitch density, linear density, fabric weight and tightness factor decrease as the stitch length increase in size due to the type of design in 
Citation: Ichetaonye SI, Ichetaonye DN, Adeakin OAS, Tenebe OG, Yibowei ME, et al. (2014) Effect of Stitch Length on the Physical Properties of Both Plain and 1 X 1 Rib Knitted Fabrics. J Textile Sci Eng 4: 177. doi:10.4172/2165-8064.1000177

Page 4 of 5

\begin{tabular}{|c|c|c|c|c|c|c|c|c|c|c|c|c|}
\hline $\begin{array}{l}\text { Fabric } \\
\text { Design }\end{array}$ & $\begin{array}{l}\text { Stitch } \\
\text { Dial }\end{array}$ & $\begin{array}{c}\text { Stitch } \\
\text { length }(\mathrm{cm})\end{array}$ & $\begin{array}{l}\text { Stitch } \\
\text { density }\end{array}$ & $\begin{array}{c}\text { Fabric } \\
\text { weigt }\left(\mathbf{g} / \mathbf{m}^{2}\right)\end{array}$ & $\begin{array}{c}\text { Linear } \\
\text { density (tex) }\end{array}$ & $\begin{array}{c}\text { Tightness } \\
\text { factor }(\sqrt{ } T / L)\end{array}$ & $\begin{array}{c}\text { Thicknes } \\
\text { factor }(\mathrm{mm})\end{array}$ & $\begin{array}{l}\text { Elastica } \\
\text { factor }\end{array}$ & $\begin{array}{l}\text { Pilling } \\
\text { Grade }\end{array}$ & $\begin{array}{l}\text { Washi } \\
\text { Wales }\end{array}$ & $\begin{array}{l}\text { kage (\%) } \\
\text { ursewise }\end{array}$ & Abrasion (g) \\
\hline A & 4 & 0.67 & 112 & 351.67 & 1.8 & 1.64 & 1.83 & 1.2 & 2.0 & 0 & 0 & 0.02 \\
\hline B & 6 & 0.84 & 104 & 310.99 & 1.6 & 1.38 & 1.85 & 1.33 & 3.0 & 10 & 14 & 0.02 \\
\hline C & 8 & 0.86 & 63 & 245.93 & 1.5 & 1.32 & 1.70 & 1.33 & 3.0 & 12 & 14 & 0.03 \\
\hline D & 10 & 0.94 & 54 & 243.21 & 1.4 & 1.22 & 1.91 & 1.38 & 3.0 & 16 & 16 & 0.04 \\
\hline
\end{tabular}

Table 1: Plain Knitted Fabric

\begin{tabular}{|c|c|c|c|c|c|c|c|c|c|c|c|c|}
\hline $\begin{array}{l}\text { Fabric } \\
\text { Design }\end{array}$ & $\begin{array}{c}\text { Stitch } \\
\text { Dial }\end{array}$ & \begin{tabular}{|c|} 
Stitch \\
ength $(\mathrm{cm})$
\end{tabular} & $\begin{array}{c}\text { Stitch } \\
\text { density }\end{array}$ & $\begin{array}{c}\text { Fabric } \\
\text { weight }\left(\mathrm{g} / \mathrm{m}^{2}\right)\end{array}$ & $\begin{array}{c}\text { Linear } \\
\text { density (tex) }\end{array}$ & $\begin{array}{c}\text { Tightness } \\
\text { factor }(\sqrt{ } T / L)\end{array}$ & $\begin{array}{l}\text { Thickness } \\
\text { Factor(mm) }\end{array}$ & $\begin{array}{l}\text { Elastica } \\
\text { Factor }\end{array}$ & $\begin{array}{l}\text { Pilling } \\
\text { Grade }\end{array}$ & $\begin{array}{l}\text { Washing S } \\
\text { Waleswise }\end{array}$ & $\begin{array}{l}\text { hrinkage (\%) } \\
\text { Coursewise }\end{array}$ & Abrasion (g) \\
\hline A & 4 & 0.8 & 70 & 1012.32 & 3.1 & 1.97 & 3.18 & 1.33 & 2.0 & 0 & 8 & 0.02 \\
\hline B & 6 & 1.04 & 66 & 998.48 & 2.7 & 1.61 & 3.55 & 1.33 & 3.0 & 4 & 8 & 0.03 \\
\hline C & 8 & 1.06 & 54 & 511.52 & 2.6 & 1.57 & 3.61 & 1.33 & 3.0 & 8 & 12 & 0.04 \\
\hline D & 10 & 1.08 & 40 & 448.17 & 2.5 & 1.52 & 3.83 & 1.33 & 3.0 & 8 & 12 & 0.05 \\
\hline
\end{tabular}

Table 2: 1x1 Rib Knitted Fabric

the order of tight, medium, slack and very slack.

Thus, the thickness factor, elastica, pilling, washing shrinkage as well as abrasion increased for plain and $1 \times 1$ rib knitted fabric which differs in chart when compared with others in the sense that the fabric gets bulkier even as stitch length increases.

However, rib fabric has a very high degree of elasticity in the course-wise direction and cannot be unraveled from the end knitted first because the sinker loops are securely anchored by the crossmeshing between face and reverse loop (Figure 11). This makes it suitable for making collars, necklines, cuffs, bottom edges of sweaters, knit hats, men's hosiery etc due to its firm and more relaxed state properties. While plain fabric can be used for making sheets, towels, sweaters, T-shirts, Men's underwear, dresses etc. Generally, there were slight differences between pilling along wales and courses, but it is too insignificant to warrant different grading. Fabric tends to pill a little more along the wales than along courses. More-over, the plain knitted fabric generally produced flatter pills lying closer to the fabric surface as well as having less abrasion effect compared to the $1 \mathrm{x} 1 \mathrm{rib}$ fabric whose pills were also fluffy and having a higher abrasion effect as the stitch length increases (Figure 12).

Furthermore, as the stitch length increase so as the elastic also having $1 \times 1$ rib exhibiting higher elastica compared to plain knitted fabric because relaxed $1 \times 1$ rib is theoretically twice as thick and half the width of an equivalent plain fabric, but it has twice as much width wise recoverable stretch. In practice $1 \times 1$ rib normally relaxes by approximately 30 percent compared with its knitting width [7-12].

\section{Conclusion}

The results analyses confirmed that, of all the parameters being studied, stitch length is the most important or decisive factors affecting the course per unit length (CPU) and wales per unit width (WPU) and also other variable such as tightness factor, gauge factor, linear density, stitch density, thickness factor, fabric weight etc.

However, the experimental result also shows that it was practically difficult to obtain the perfectly stable state for plain knitted fabric. This was not only because the knitted structure could not fully relaxed due to high internal restrictive force but also due to the fact that different drying processes and condition would result in different fabric dimension. Thus, stitch length has greater effect on both $1 \times 1$ rib and plain knitted fabric but more on $1 \mathrm{x} 1 \mathrm{rib}$ in the sense that the lesser the stitch length, the more compact the fabric structures is, the higher

\section{Course}

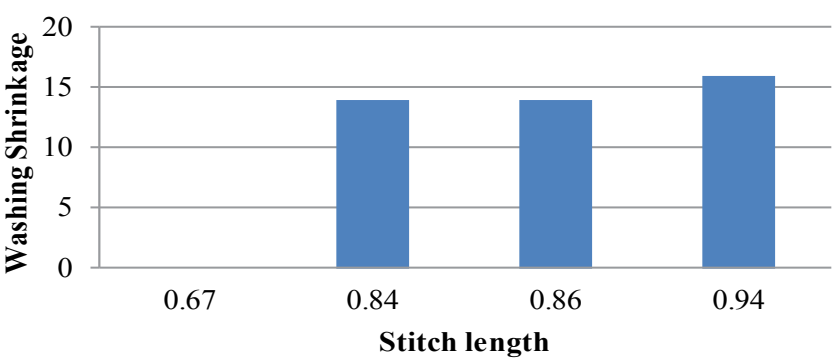

Figure 11: Washing Shrinkage with respect to Stitch length

\section{Course}

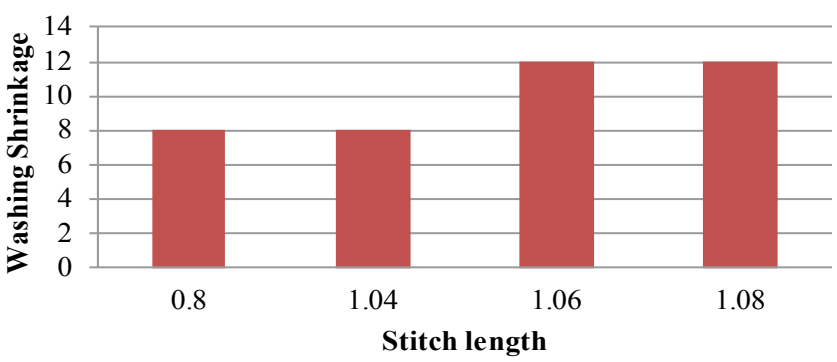

Figure 12: Washing Shrinkage with respect to Stitch length

the stitch density and fabric weight but the higher the stitch length, the more loose the fabric becomes and the lesser the stitch density and fabric weight.

\section{References}

1. David JS (1982) Knitting Tech.

2. Nutting TS, Leaf GA (1964) A Generalised Geometry of Weft-Knitted Fabrics Journal of the Textile Institute 55: T45.

3. Poole HB, Brown P (1978) The Dimensions of $1 \times 1$ Rib Fabrics, Part I: Literature Survey. Textile Research J 48: 339-343.

4. Fletcher HM (1954) The Relationship of Geometry of Plain Knit cotton Fabric to Its Dimensional Change and Elastic Properties Textile Research J 24: 729.

5. Batchelor CW (1972) Double jersey Knitting and Patterning Hos Trade J 234.

6. Portrait of the Channel Islands.

7. Fletcher HM, Roberts SH (1965) Elastic Properties of Plain and Double Knit Cotton Fabrics Textile Research J 35: 497. 
Citation: Ichetaonye SI, Ichetaonye DN, Adeakin OAS, Tenebe OG, Yibowei ME, et al. (2014) Effect of Stitch Length on the Physical Properties of Both Plain and 1 X 1 Rib Knitted Fabrics. J Textile Sci Eng 4: 177. doi:10.4172/2165-8064.1000177

Page 5 of 5

8. Smirfitt JA (1965) Worsted $1 \times 1$ Rib Fabrics, Part II Some Physical Properties. J Textile Institute 56: T298-T313.

9. Mundun DL (2002) The Geometry and Dimensional Properties of Plain Knit Fabrics - J Textile Institute 50: T448.
10. Dart T (1960) An Entropy Stress Study of various Textile Fibers. Textile Resesrch J 30: 372.

11. Abbott (1964) The Relationship between Fabric Structure and Ease - of - Care Performance of Cotton Fabrics. Textile research J 34 : 1049.

12. Hearle F (1969) Structural Mechanics of Fibres and Yarns and Fabrics 1: 403. 